\title{
Territorialidades migrantes: um estudo antropológico sobre a Copa Peru-Rio
}

\section{Resumo}

A Copa Peru-Rio é um campeonato de futebol organizado por imigrantes peruanos que residem no Rio de Janeiro. $O$ evento acontece todos os anos ao longo do mês julho, tendo como principal motivação celebrar o "día de la patria", o dia da independência do Peru. Reunidos em torno deste símbolo nacional, os peruanos no Rio de Janeiro fazem do futebol, esporte admirado tanto no país de origem como no de destino, um instrumento para construir espaços de interação e de sociabilidade no contexto de imigração. Este artigo tem como objetivo analisar a Copa Peru-Rio como um evento que, além da dimensão lúdica, tem a capacidade de agregar peruanos que encontram no futebol uma oportunidade para se familiarizar com o espaço da cidade e se (re)territorializar na experiência migratória. Entendendo a (re)territorialização como a possibilidade de se apropriar simbolicamente do território (HAESBERT, 2006), este trabalho analisa que, na Copa Peru-Rio, os peruanos reafirmam uma origem nacional específica, diferente da brasileira. Nesta origem nacional reivindicada, as diferenças regionais, de gênero e de raça não desaparecem: elas são ressignificadas no convívio entre peruanos, brasileiros e estrangeiros de outras nacionalidades e são expressas na dinâmica do campeonato. $O$ presente trabalho se baseia na observação participante realizada na Copa Peru-Rio nas edições de 2011 e 2012 e no trabalho de campo etnográfico realizado de abril de 2011 a dezembro de 2012.

Palavras-chave: Territorialidades; Peruanos; Futebol; Imigração; Rio de Janeiro.

\section{Para citar este artigo:}

DANIEL, Camila. Territorialidades migrantes: um estudo antropológico sobre a Copa Peru-Rio. Revista PerCursos. Florianópolis, v. 15, n.28, p. 120 -145. jan./jun. 2014.

\section{DOI: $10.5965 / 1984724215282014120$}

http://dx.doi.org/10.5965/1984724215282014120

\section{Camila Daniel}

Doutora em Ciências Sociais pela Pontifícia Universidade Católica do Rio de Janeiro. Professora da Universidade Federal Rural do

Rio de Janeiro - Brasil. camiladaniell@gmail.com 


\title{
Migrants territorialities: a anthropological study about Peru - Rio Cup
}

\begin{abstract}
The Peru -Rio Cup is a soccer tournament organized by Peruvian immigrants living in Rio de Janeiro. The event takes place every year during the month of July, and its primary motivation is to celebrate the "día la patria", the Independence Day of Peru. Gathered around this national symbol, Peruvians in Rio de Janeiro transform soccer, a sport admired in both countries of origin and of destination, a mean to construct spaces of interaction and sociability in the context of immigration. This article aims to analyze the Peru Rio Cup as an event that, beyond its playful dimension, has the ability to aggregate Peruvians. In such experience, they have soccer as an opportunity to become familiar with the city and reterritorialize themselves according to their migratory experience. As (re)territorialization as the possibility of appropriating the territory symbolically ( HAESBERT, 2006), Peruvian reaffirm a particular national origin, different from the Brazilian Peru - Rio Cup. In this claimed national origin, regional, gender and race differences did not disappear: they are re-signified in relationships Peruvians, Brazilians and foreigners of other nationalities construct, making it clear in the dynamics of the championship. This study is based on participant observation conducted in the in 2011 and 2012 editions of Peru -Rio Cup and led to my doctoral thesis on the migratory experience of Peruvian students in Rio de Janeiro.
\end{abstract}

Keywords: Territorialities; Peruvians; Football; Immigration; Rio de Janeiro. 


\section{Introdução}

Todos os anos, nos domingos de julho, as listras rubro-brancas com o brasão de armas ao centro da bandeira nacional do Peru enfeitam as grades do campo três do Aterro do Flamengo, no Rio de Janeiro. Criado nos anos 1960, a partir de um projeto de modernização da cidade, o Aterro se tornou uma referência de área de lazer para a população do Rio de Janeiro, inclusive como espaço para a prática do futebol amador, as chamadas "peladas" (ALMEIDA, 2012). Apropriando-se dos usos e sentidos que os cariocas fazem do Parque do Flamengo - como também é chamado o Aterro do Flamengo -, muitos peruanos que vivem na cidade fazem do parque o lugar para encontrar os amigos e praticar o esporte que agita corações tanto no Peru, quanto no Brasil. Para muitos desses imigrantes, ter a oportunidade de reunir os amigos em torno da bola e do gramado representa uma importante dimensão da vida social no contexto de imigração, quando investem o tempo em atividades lúdicas e constroem sociabilidades a partir do lazer.

Ao mesmo tempo em que compartilham com os cariocas os usos do Aterro do Flamengo, como a prática da "pelada", os peruanos também encontram a oportunidade de ressignificar os sentidos do espaço público e da prática futebol no Rio de Janeiro, principalmente no contexto da Copa Peru-Rio. Realizado anualmente para comemorar o dia da independência do Peru, cuja data é dia 28 de julho, o evento se tornou uma tradição dentro da comunidade e em 2013 chegou à sua sétima edição. No período do campeonato, o Aterro do Flamengo, importante ponto de encontro dos cariocas, assume intensas cores, contornos e sonoridades estrangeiras. Apesar de o futebol ser o protagonista da festa dentro do campo, do lado de fora, a Copa Peru-Rio tem seu cenário envolvido por outros elementos que remetem à origem nacional peruana. Enquanto as equipes competem em campo para ganhar mais pontos e avançar na tabela do campeonato, do lado de fora, outros peruanos e peruanas se encontram para conversar, saborear os pratos típicos do país, ouvir e dançar ritmos populares de seu país. Ao fundo do campo figuram as curvas do Pão de Açúcar, um dos mais famosos pontos turísticos da cidade do Rio de Janeiro. 
Em 2011 e 2012 frequentei algumas partidas da Copa Peru-Rio. Na ocasião, eu realizava o trabalho de campo etnográfico - que durou de abril de 2011 a dezembro de 2012 - para minha pesquisa de doutoramento, em que analisei a experiência migratória de peruanos/as no Rio de Janeiro como estudantes universitários (DANIEL, 2013). O trabalho de campo envolveu minha assídua e ativa participação em reuniões e eventos organizados por peruanos, principalmente os oriundos da classe média escolarizada. Alguns eventos, como o da Copa Peru-Rio, era frequentado por um público mais diversificado em termos de classe, idade, local de origem, etc.

Este trabalho foi desenvolvido a partir da metodologia de observação participante, que privilegia a construção de uma relação próxima e empática entre o pesquisador e os interlocutores, no processo de "tornar o exótico familiar e o familiar exótico" (DA MATTA, 1978, p. 28). Os dados aqui apresentados foram sistematicamente anotados em caderno de campo, coletados através da observação e da conversa informal com frequentadores das edições de 2011 e 2012 da Copa Peru-Rio e posteriormente analisados. Diante do fato de não haver outros trabalhos sobre a imigração peruana no Rio de Janeiro, o presente artigo se concentra na análise do material etnográfico registrado no caderno de campo. Também foram incluídos trechos de entrevistas semiestuturadas realizadas com os que vieram ao Rio de Janeiro e que subsidiou minha tese de doutorado.

No ano de 2011, as partidas da Copa Peru-Rio foram um importante espaço no meu processo de aproximação com peruanos na cidade. Naquele período, eu já havia conhecido alguns que estudavam na PUC-RJ, universidade onde cursei o doutorado, além de outros que trabalhavam como vendedores ambulantes em diferentes áreas da zona central e norte da cidade. Nas partidas do campeonato, tive a oportunidade de conversar com eles de forma mais tranquila do que quando nos encontrávamos na universidade ou no trabalho. Muitos dos que havia conhecido previamente demonstravam muita empolgação ao me encontrar no evento: eles faziam questão de me apresentar a seus amigos, como "a brasileira que fará uma pesquisa sobre os peruanos" e me cobravam para torcer por seu time. 
O presente artigo tem como objetivo analisar a Copa Peru-Rio e as formas de sociabilidades construídas em torno dela como elementos que apresentam aos peruanos a possibilidade de se reterritorializar, apropriando-se cultural e simbolicamente do território (HAESBERT, 2006) onde vivem a experiência migratória: a cidade do Rio de Janeiro. Assim, o campeonato carrega a potencialidade de produzir entre eles um sentimento de familiaridade com a cidade e com outros conterrâneos que vivem nela. No entanto, o processo de reterritorialização, quando acontece, não se dá num vazio, mas segundo as referências aprendidas no Peru e ressignificadas no Brasil. Isto significa que a reterritorialização é tangenciada pelas hierarquias de classe, raça e gênero que vigoram na sociedade de origem e dialogam com as hierarquias (re)produzidas no Brasil. Elas não desaparecem, mas são o pano de fundo das relações que os peruanos constroem entre si na cidade.

\section{Cidade, mobilidades e territorialidades}

$\mathrm{Na}$ compressão espaço-tempo fomentada pelos avanços das tecnologias de comunicação, informação e de transporte que caracterizam a modernidade em sua fase globalizada, a metrópole se torna palco de processos sociais, econômicos, políticos e culturais que ultrapassam os limites temporais e espaciais da própria cidade e do Estadonação. A mobilidade do capital, a internacionalização da produção e a financeirização da economia provocaram uma profunda reorganização das atividades econômicas no tempo-espaço das cidades. A mobilidade do capital também repercutiu no mercado de trabalho internacional, impulsionando a migração de pessoas que buscam, além das fronteiras do seu país de origem, oportunidades de trabalho, seja em setores altamente qualificados, seja como mão de obra em setores mal remunerados. Para os indivíduos, a metrópole pode, ao mesmo tempo, provocar um sentimento de desenraizamento, devido à diversidade de estímulos nervosos, à progressiva racionalização das relações sociais e ao rompimento dos laços sociais tradicionais que ela propicia (SIMMEL, 1979), mas também pode se tornar o lugar do encontro, através do qual os indivíduos elaboram, no urbano, novas formas de pertencimentos e identidades (LEFÉBVRE, 2004). 
Na realidade peruana, a ida de pessoas ao exterior faz parte do imaginário de construção de nação das elites nacionais. Para elas, ir para outros países, principalmente para a Europa, era uma forma de renovar seu prestígio e status (ALTAMIRANO, 2000). A imigração se tornou um fenômeno de massa no Peru nos anos 1980, quando o país passou por uma severa crise econômica e política. A crise política culminou com a ação violenta de grupos armados, como o Sendero Luminoso, e do próprio Estado, com o "autogolpe" impetrado pelo então presidente Alberto Fujimori (TANAKA, 1995). Além da derrubada da democracia e da violência militar e paramilitar, o Peru também viveu uma profunda crise econômica, que resultou no profundo empobrecimento da qualidade de vida de seus cidadãos. A instabilidade política, os altos índices de inflação e a crescente deterioração das condições de vida levaram muitos peruanos - das mais diferentes classes sociais, origens étnicas e regiões do país - a buscar no exterior uma alternativa de vida. Neste cenário, os destinos mais procurados foram os EUA, a Argentina, a Espanha e o Chile (PARREGAAD, 2008).

No exterior, os peruanos constroem diferentes dinâmicas de sociabilidade, as quais, algumas vezes, privilegiam a construção de laços de afinidade com outros conterrâneos que também vivem a experiência de estar longe do país. Em muitos casos, a consolidação de uma rede migratória entre pessoas do mesmo país se materializa na reorganização do território no país de imigração, levando, por exemplo, à construção dos chamados "bairros étnicos", áreas da cidade em que os imigrantes se concentram para trabalhar e viver, estabelecendo, inclusive, uma série de serviços específicos para atendêlos, como restaurantes de culinária do país de origem. Segundo Sassen (2001), os bairros imigrantes se formam no contexto de transformação da dinâmica do trabalho no capitalismo global, que incorpora a mão de obra estrangeira em atividades manuais e pouco qualificadas do mercado de trabalho internacional, que, por mal remuneradas que são, obrigam os trabalhadores imigrantes a organizar, por conta própria, estratégias para suprir a demanda por moradia. A imigração peruana está inserida neste contexto, pois muitos dos que saem do Peru o fazem através da sua incorporação em ramos do mercado de trabalho internacional mal remunerado e pouco qualificado, muitas vezes abaixo de 
suas qualificações. Assim, além da dimensão cultural, os bairros étnicos estão intimamente relacionados à inserção econômica dos imigrantes nas grandes cidades.

Se, por um lado, os bairros que concentram imigrantes peruanos, como Patterson, em Nova Jersey (EUA), Lima Chica, em Santiago (Chile) ou o entorno da Praça da República, em São Paulo, são formados a partir da demanda dos imigrantes por uma moradia que possam pagar com seus salários e que lhes permita o deslocamento até o local de trabalho com o menor custo de transporte possível, por outro, estes bairros também se apresentam como uma alternativa para construir diferentes formas de se sentir parte do espaço da cidade, através do comércio de produtos do país de origem, restaurantes, discotecas, empresas de envio de remessas, etc. Assim, os imigrantes elaboram a possibilidade de construir novas territorialidades no contexto urbano.

Haesbert (2006), discutindo o que denominou de "mito da desterritorialização", ressalta que não existe uma relação automática entre a mobilidade das pessoas pelo espaço e a desterritorialização, termo muitas vezes empregado para se referir às pessoas que se deslocam por diferentes países. Mais do que descrever as pessoas no espaço, o território e, portanto, a territorialização, se refere a uma "relação de poder mediada pelo espaço" (HAESBERT, 2003, p. 259), em que os indivíduos assumem o controle sobre "as bases territoriais de reprodução e referência" (HAESBERT, 2006 p. 255). Portanto, para o autor, a desterritorialização não significa um simples aumento de pessoas viajando pelo mundo, já que as viagens e deslocamentos internacionais são permeadas por relações de poder. Os desterritorializados são os indivíduos que, ao se moverem internacionalmente, são impedidos se apropriar cultural e simbólica do espaço. No contexto da globalização, o espaço é penetrado por processos virtuais que inserem o movimento na dinâmica dos territórios. Por isso, “[...] territorializar-se significa também, hoje, construir e/ou controlar fluxos/redes e criar referenciais simbólicos num espaço em movimento, no e pelo movimento" (Id., p. 280). Se os chamados "bairros étnicos" podem carregar a possibilidade de os imigrantes se reterritorializarem no contexto da imigração, eles também podem se tornar espaços de desterritorilização, quando se transformam em guetos. Os guetos são uma "desterritorialização in situ": uma desterritorialização sem mobilidade. Um bairro se torna um gueto quando os indivíduos temem sair do seu 
interior e se transforma no único lugar onde eles se sentem seguros, incluídos e pertencentes.

Diferentemente de cidades como Nova Iorque, Buenos Aires, Santiago ou São Paulo, no Rio de Janeiro não existe um bairro em que a população peruana esteja tão concentrada a ponto de se distinguir na dinâmica do território urbano. No Rio de Janeiro, eles residem em diferentes partes da cidade, convivendo cotidianamente com as populações locais. A escolha do local de residência está relacionada a um conjunto de fatores, como a motivação que os levou cidade, o contato prévio que estabeleceram com pessoas que já moravam no local e as condições econômicas de quando chegaram à cidade. Um elemento que caracteriza a imigração peruana no Rio de Janeiro, e também em outros países do mundo, é sua heterogeneidade cultural, social, política e econômica.

Ainda que tenham a mesma origem nacional e vivam no exterior, os imigrantes nunca €onformam um todo monolítico e completamente uniforme, como mostra, por exemplo, Busse (2011), ao estudar a complexa relação de gênero entre imigrantes peruanos na região de Patterson, EUA, e a discriminação a que as peruanas, mães solteiras, estão sujeitas dentro do bairro. A heterogeneidade da imigração peruana no Rio de Janeiro fica evidente também na forma como escolhe o lugar de moradia, que varia desde bairros de classe média da zona sul, norte, oeste, como Copacabana, Tijuca, Vila Isabel e Barra da Tijuca, até bairros e áreas populares, como as diferentes favelas da zona sul do Rio de Janeiro, bairros que concentram as classes populares nos municípios de Nova Iguaçu e São Gonçalo.

No Rio de Janeiro, os peruanos com quem convivi eram muito enfáticos ao analisar a dinâmica de relação entre as pessoas da mesma origem nacional na cidade. Sempre me alertavam que a população peruana é muito diversificada e que eu iria encontrar muito preconceito entre eles próprios. Devidamente alertada logo pelos primeiros peruanos que conheci, comecei o trabalho de campo atenta para compreender as heterogeneidades dessa imigração no Rio de Janeiro. Segundo dados do Consulado, cerca de cinco mil vivem na região de sua atuação, que abrange os estados do Rio de Janeiro e Espírito Santo. Estes dados contabilizam apenas os que tem registrados, não incluindo, portanto, os indocumentados ou os documentados que não se registraram. 
Um elemento marcante entre os peruanos no Rio de Janeiro é a significativa predominância de pessoas documentadas. Entre os registrados, segundo o Consulado, predominam dois perfis: um, o dos que chegaram ao Rio de Janeiro como estudantes universitários - muitos deles se tornam imigrantes depois de formados -; outro, dos que já chegam à cidade como imigrantes e se dedicam ao comércio informal ambulante, os chamados "artesanos".

Uma dificuldade para se conhecer de maneira mais precisa as características das populações imigrantes no Brasil - não apenas a peruana - é a deficiência de dados quantitativos sobre o tema. A própria embaixada do Peru no Brasil reconhece as dificuldades que tem em conhecer mais profundamente a própria população peruana no Brasil. Por conta disso, já chegou a solicitar dados à Polícia Federal, responsável pela regularização dos estrangeiros no Brasil, mas sem sucesso. No caso específico, os dados do consulado não são sistematicamente organizados, a ponto de não ter como reconhecer, do universo total, por exemplo, quantos chegaram como estudantes e transformaram seu visto em permanente ou quantos trabalham em atividades informais. Por isso, este trabalho não se propõe fazer afirmações quantitativas, mas se baseia integralmente em dados qualitativos, que incluem minha experiência de trabalho de campo e as experiências de imigração que observei e as que foram relatadas pelos próprios imigrantes no Rio de Janeiro.

Na experiência do trabalho de campo, encontrei peruanos com perfis diversos, além dos que fugiam do tipo predominante e no Rio de Janeiro trabalham como costureiros, empregadas domésticas, profissionais em empresas de petróleo, etc. Os eventos peruanos, no entanto, são frequentados principalmente por trabalhadores do comércio informal e estudantes. Cotidianamente, estes dois grupos estabelecem pouco contato e é nos momentos de celebrações de datas cívicas, como a Copa Peru-Rio, que eles se encontram. 


\section{Futebol: conexões entre Peru e Brasil}

O futebol é uma atividade lúdica que faz parte da vida cotidiana de muitos peruanos no Peru e no Brasil. Ainda no país de origem, muitos deles tinham o hábito de acompanhar pela televisão partidas de campeonatos profissionais nacionais, regionais e internacionais, como o campeonato peruano, o brasileiro e o europeu. Para os aficionados de futebol, os campeonatos que reúnem diferentes países do continente sulamericano, como a Copa Libertadores da América e a Copa Sul-Americana, têm um lugar de destaque em sua preferência, pois esta é a chance que têm de ver seus times jogando contra grandes equipes de países que se destacam no cenário internacional do futebol, como o Brasil e a Argentina. Para os peruanos no Brasil, os campeonatos regionais também representam uma grande oportunidade para ver seus times jogando no Brasil, como aconteceu em 2011, quando o time peruano "Universitario" jogou contra a equipe do Vasco da Gama. Os torcedores da equipe peruana que moravam no Rio de Janeiro divulgaram amplamente o jogo nas redes sociais e se organizaram para ir juntos ver o time do país de origem jogar.

Nas viagens que fiz ao Peru ao longo do trabalho de campo, não raras vezes, os homens, sobretudo, me perguntavam sobre o futebol brasileiro, principalmente depois de dois fatos: a escolha do Brasil como sede da Copa do Mundo de 2014 e a contratação do peruano Paolo Guerrero para jogar no clube Corinthians. Reconhecendo o futebol como uma das características marcantes do Brasil por sua qualidade e notoriedade internacional, os peruanos se orgulhavam de ter um compatriota contratado por uma grande equipe brasileira. O orgulho é ainda maior quando o jogador demonstra um bom desempenho, participando ativamente das vitórias conquistadas pela equipe. Além disso, a escolha do Brasil como sede da Copa do Mundo de 2014 contribuiu ainda mais para a difusão de um imaginário, entre eles, do Brasil como um centro futebolístico, país que produziu grandes nomes como Pelé e Ronaldinho.

Muitos dos que escolheram o Rio de Janeiro como destino não tinham uma ideia exata de como seria o País, embora compartilhassem uma imagem de país acolhedor, com belas praias, um empolgante carnaval e um brilhante futebol, como discuti em minha tese de doutorado (DANIEL, 2013). Muitos deles já conheciam profundamente o futebol 
brasileiro antes de chegar ao País e aqui continuam a fazer dele parte de sua vida cotidiana como atividade de lazer, seja assistindo a partidas profissionais pela TV, ao vivo, ou jogando informalmente com os amigos.

No Rio de Janeiro, são muitos os peruanos que se juntam para jogar futebol. Reunindo em campo exclusivamente homens, as partidas de futebol são organizadas por diferentes grupos de afinidades que têm algum tipo de relação fora dos campos. Em geral, as partidas de futebol entre eles ocorrem em diferentes partes da zona sul da cidade e são realizadas a partir de grupos que se conheceram de diferentes maneiras, como: residir em áreas próximas; desenvolver o mesmo tipo de atividade econômica; integrar a mesma rede de relacionamentos; ter chegado à cidade no mesmo período; provir do mesmo local de origem; pertencer à mesma classe social, etc.

No bairro da Gávea, há um grupo de peruanos que se encontra às quartas-feiras para entrar em campo. Este grupo é formado majoritariamente por alunos da PUC-Rio, que aproveitam as dependências da universidade para praticar o esporte de que tanto gostam. Nas imediações do Centro Brasileiro de Pesquisas Físicas (CBPF) também há um grupo de estudantes da instituição que se encontra para jogar futebol. Outro ponto de encontro de peruanos que apreciam o esporte é o Aterro do Flamengo. Duas vezes por semana, um grupo dos que trabalham como vendedores ambulantes - e que vivem no entorno da Lapa, região central da cidade -, se encontra à noite para jogar. Além dos grupos que jogam periodicamente, há outros que eventualmente marcam para se encontrar e praticar o esporte. Neste caso, as partidas não têm uma periodicidade previamente definida e acontecem de maneira contingente.

O que há em comum entre os diferentes grupos que jogam futebol é que são compostos exclusivamente de homens, que se conheceram a partir de uma rede comum de relações que se construiu a partir de sua inserção na cidade. Entre os peruanos com quem convivi de maneira mais intensa ao longo do período em que realizei o trabalho de campo etnográfico, as redes de relações eram formadas majoritariamente por peruanos, mas também por brasileiros e estrangeiros de outras nacionalidades, principalmente latino-americanas, como colombianos, argentinos, chilenos e equatorianos. 
Assim, os peruanos que querem jogar futebol e chegaram à cidade como estudantes universitários provavelmente irão encontrar parceiros de jogo entre outros conterrâneos, colegas de universidade, e as partidas serão realizadas num local próximo à sua residência ou à universidade. Já aqueles que estão na cidade como trabalhadores irão, muito possivelmente, compor equipes com outros peruanos que compartilham uma experiência migratória vinculada ao trabalho e irão jogar sua "pelada" em locais próximos às áreas por onde costumam circular, como acontece com os vendedores ambulantes que jogam futebol no Aterro do Flamengo. Muitos deles vivem na Lapa e trabalham em diferentes partes do centro da cidade e da zona sul, principalmente no entorno das praias cariocas. Em outras palavras, apesar de o futebol ser um esporte apreciado por grande número de peruanos - no Peru e também no Brasil -, sua prática, no contexto de imigração, é permeada de diversos elementos que ultrapassam os limites das quatro linhas que delimitam o campo de futebol. Se no dia a dia estes elementos estão difusos por diferentes partes da cidades, em julho, eles se concentram em torno da realização da Copa Peru-Rio.

\section{Copa Peru-Rio: a organização}

A organização da Copa Peru-Rio é uma iniciativa de um grupo de amigos que joga futebol no Aterro do Flamengo às quintas-feiras à noite, depois que saem do trabalho. Muitos deles trabalham no comércio ambulante e moram próximos uns dos outros na Lapa, região do centro. A Copa Peru-Rio, no entanto, não se restringe a este grupo de amigos, nem a peruanos. Dela participam diferentes equipes. No ano de 2011, nove times competiram pela taça de campeão, uma delas formada por equatorianos; em 2012, foram oito as que lutaram pelo título. Todas as equipes poderiam ter até dois jogadores brasileiros.

De acordo com o regulamento, cada equipe deve inscrever pelo menos 12 jogadores, chegar 15 minutos antes do início da partida e jogar devidamente uniformizada (com camisa numerada e short). Cada partida tem duração de 40 minutos, divididos em dois tempos de 20 minutos, com intervalo de cinco minutos entre cada tempo. Cada time 
deve entrar em campo com seis jogadores: cinco na linha, e um goleiro. Para participar do campeonato, as equipes devem contribuir com o valor de $\mathrm{R} \$ 120,00$ para cobrir custos. O time campeão da copa será o que acumular mais pontos, de acordo com o número de vitórias, e receberá, como recompensa, um troféu. Em caso de empate em número de partidas vencidas, o desempate será realizado a partir da contagem do saldo de gols. As regras do jogo, bem como a tabela dos jogos, os pontos acumulados, a foto das equipes participantes e outras informações sobre o evento foram publicadas na internet, no site do evento, nos anos de 2011 e 2012. Em 2013, além do site do evento, as informações do campeonato foram compartilhadas pelo facebook.

Para realizar o evento, a comissão organizadora solicita à Prefeitura do Rio de Janeiro uma autorização para reservar o campo onde deverão ocorrer as partidas. Depois da devida autorização, os organizadores divulgam entre a comunidade peruana a data em que estarão abertas as inscrições das equipes. Na divulgação do evento, o Consulado Geral do Rio de Janeiro contribui, enviando mensagem, via e-mail, aos peruanos registrados, repassando as informações que os organizadores do evento pedem. Além disso, muitos tomam conhecimento da realização da Copa Peru-Rio através de sua rede de amigos, principalmente daqueles que costumam jogar futebol com outros compatriotas. As redes de relacionamento são o principal meio de transmissão de informação entre os imigrantes peruanos, funcionando de forma horizontal e tendo a capacidade de abranger não apenas os registrados no consulado, mas também os recémchegados, não registrados e indocumentados.

Além do apoio formal que recebe do consulado - que se compromete apenas com a divulgação do evento nos meios de comunicação oficiais (e-mails e mural interno ), a realização da Copa Peru-Rio é também apoiada por pequenos empresários peruanos, como a proprietária do restaurante IntiWasi, das lojas de artesanato IntiVocê e Kiswar e da empresa que fornece o cartão de chamadas telefônicas La Peruanita. Os pequenos empresários contribuem também com a divulgação do evento e/ou com a doação de produtos de suas lojas, que os organizadores podem revender para angariar mais fundos. A Copa Peru-Rio é, portanto, um evento autogestionado - os próprios imigrantes são responsáveis por toda a organização do evento - e procuram, entre eles, formas de arcar 
financeiramente com os custos e de divulgá-lo entre os peruanos no Rio de Janeiro. Atualmente, a copa já é um evento que faz parte da agenda da comunidade, juntamente com outros dois: a festa em comemoração ao dia da independência do Peru, as "fiestas patrias" e a celebração do Señor de los Milagros, santo padroeiro do Peru. Os três eventos são realizados anualmente, entre a Lapa e a zona sul da cidade do Rio de Janeiro e conseguem reunir peruanos com os mais diferentes perfis.

\section{As mulheres na "Copa"}

Apesar de o campeonato contar apenas com equipes formadas por homens, as mulheres estão presentes em todas as partidas. Mais do que um campeonato de futebol, o evento tem a capacidade de reunir peruanos/as, mesmo que não tenham nenhuma relação direta com o futebol. Este é o caso das mulheres. Como o campeonato é disputado apenas por homens, elas não entram em campo. Apesar disso, são presença assídua no campeonato. Costumam participar da Copa Peru-Rio de diferentes maneiras: como plateia, torcendo pelas equipes de seus maridos, namorados ou amigos; como comerciantes informais de pratos típicos da culinária peruana; como consumidoras de comida peruana; como dançarinas.

Dentre as mulheres participam da copa acompanhando namorados ou maridos em campo, algumas são brasileiras. Para estas, ir aos jogos representa uma oportunidade de conhecer mais da cultura peruana e das relações que seus companheiros constroem com outros peruanos. Para muitas, será na copa que elas vão experimentar, pela primeira vez, pratos e bebidas peruanas e conhecer a rede de amizade do companheiro. Quando num mesmo time vários jogadores vão ao evento acompanhados de suas namoradas/esposas, é comum que elas fiquem conversando entre si, enquanto os homens formam um círculo fechado entre eles, comunicando-se em espanhol e deixando suas companheiras de fora.

Enquanto as mulheres brasileiras que frequentam a copa o fazem principalmente para acompanhar seus parceiros, entre as peruanas há mulheres que também vão ao evento porque o parceiro faz parte de uma das equipes que jogarão, mas também há outras que veem no evento a oportunidade de encontrar os/as amigos/as e saborear os 
pratos do país de origem, vendidos no entorno do campo. Mesmo quando companheiras de algum competidor, as mulheres peruanas raramente vão ao campeonato apenas como acompanhantes. Para elas, a Copa Peru-Rio é também oportunidade de encontrar seus/suas próprios/as amigos/as e (re)construir no contexto de imigração formas de sociabilidade que remetem ao Peru.

As mulheres cujos parceiros competem pela taça compartilham a emoção dos jogos do lado de fora do campo, na torcida. Durante as partidas dos outros times, elas costumam conversar entre si; porém, quando a partida do parceiro começa, todas se concentram para torcer pela vitória dele. Em 2011, um grupo de esposas e namoradas (peruanas e brasileiras) de uma determinada equipe decidiu torcer de forma mais organizada. Elas levaram cartazes, fizeram camisas personalizadas como o nome do time e levaram pompons e, como líderes de torcida, gritavam em coro palavras de estímulo e encorajamento aos parceiros.

Uma particularidade da Copa Peru-Rio é que, uma vez que as equipes são formadas segundo redes de afinidade, a interação entre elas é limitada e esporádica. Antes e depois das partidas, cada equipe costuma manter-se unida entre si, conversando, comendo e bebendo. Esta dinâmica de relação predominante entre os homens se estende para a relação das mulheres brasileiras e peruanas que vão torcer pelos parceiros. As mulheres, principalmente as brasileiras, mantêm seu círculo de interação concentrado nas namoradas e esposas dos outros jogadores da equipe do seu namorado/marido. Já algumas peruanas circulam por outras redes de relações, mas, ainda assim, mantêm o centro de interação em torno da equipe que entra em campo. Quando os jogadores de uma mesma equipe têm esposas e namoradas brasileiras e peruanas, elas costumam interagir entre si, como o grupo que, em 2011, torcia de forma organizada. Assim como a interação entre as equipes é limitada, também o é a relação entre as mulheres que vão assistir às partidas. As equipes representam redes de relações delimitadas, das quais as mulheres também participam.

Uma tradição é que, nos domingos do campeonato, senhoras peruanas com experiência em cozinhar vendam pratos tradicionais do país no entorno do campo onde acontecem as partidas. Por isso, alguns peruanos vão para o campeonato apenas para 
comer. Para muitos deles, a comida constitui um elemento central na noção de pertencimento, o que faz com que os eventos nos quais são servidos pratos do país sejam geralmente os mais amplamente frequentados (DANIEL, 2013). A sra. Beni, as sobrinhas e irmãs ficaram muito populares no Rio de Janeiro por prepararem pratos peruanos e vendê-los, principalmente, em eventos festivos peruanos, como a Copa PeruRio. Um dos organizadores do campeonato é casado com uma das sobrinhas da sra. Beni. Durante as partidas, elas organizam pequenos estandes; com grandes recipientes térmicos, vendem pratos peruanos como papa a la huacaína, ceviche, anticuchos e arroz con pollo.

No dia do encerramento do evento, as mulheres também participam da Copa Peru-Rio, não no campo, mas na dança. Nas edições de 2011 e 2012 (e também na de 2013), os organizadores do evento convidaram o grupo Sayari de Danzas Peruanas para apresentar números de dança folclórica peruana - como a marinera, o tondero, o huayno e o festejo -, para fechar o campeonato celebrando suas tradições. Embora as mulheres desempenhem um papel importante na dança, em nenhum dos números apresentados em 2011 e 2012 elas dançaram sozinhas. Em todos eles, os homens que integram o grupo Sayari também dançaram, assim como houve quem também torcesse pelas equipes em campo - porém, não com camisas personalizadas e pompons. A única atividade exercida exclusivamente por mulheres nas edições de 2011 e 2012 da Copa Peru-Rio foi o preparo e a venda de pratos típicos.

\section{Relações sociais dentro e fora de campo}

Na primeira edição da Copa Peru Rio a que assisti, em 2011, observei que as equipes estavam circunscritas a determinados grupos de afinidades. Meses antes do início do campeonato, conheci dois irmãos oriundos de Cusco que vendiam bijuterias na passarela do shopping Nova América, em Del Castilho, zona norte. Sempre que eu passava pelo shopping, que fica próximo da minha casa, eu conversava um pouco com os dois. Numa das conversas, eles me contaram que moravam na Lapa e me convidaram para ir às partidas de futebol às quintas-feiras, no aterro. Agradeci o convite, mas nunca 
fui ao jogo deles. Na Copa Peru-Rio 2011, eu os reencontrei. Eles compunham uma equipe com outros dois irmãos de Cusco que trabalham com confecção e venda de roupa. Os quatro comentaram que costumam trabalhar juntos, viajando por diferentes partes do Brasil, vendendo seus artigos em feiras de exposição agropecuária. Os outros integrantes do time também eram de Cusco e trabalhavam como vendedores ambulantes.

Além de conhecer alguns integrantes desta equipe, eu já tinha amizade com alguns dos integrantes de um time formado por peruanos que chegaram ao Rio como estudantes. Todos os jogadores deste time moram em áreas de classe média do Rio Copacabana, Laranjeiras, Vila Isabel - e da região metropolitana - Niterói -, onde exercem atividades profissionais qualificadas como dentista, administrador, publicitário, engenheiro. Grande parte chegou ao Rio de Janeiro entre final dos anos 90 e início de 2000.

Estes dois times despertaram minha atenção. Primeiro, porque eu conhecia os jogadores, e naquele momento fui apresentada a suas namoradas. Segundo, porque eles não se relacionavam entre si. Durante as partidas, os times se dividem pelo entorno da quadra em pequenos grupos, que agregam os próprios jogadores, as namoradas e esposas, os filhos e, às vezes, alguns amigos. Na final da Copa Peru Rio 2011, a equipe formada pelos cusquenhos se concentrou numa ponta da quadra. A equipe dos exestudantes, na outra. Como eu conhecia pessoas dos dois times, e as namoradas dos jogadores esperavam que eu fizesse companhia a elas, passei a tarde inteira me deslocando de uma ponta a outra da quadra, o que, no fim da tarde, me deixou exausta.

Num determinado momento, a namorada do Fernando, um dos jogadores cusquenhos, ficou sozinha. Ela reclamou que "sumi”: eu saí de perto dela e demorei a voltar. Incomodada pela cobrança e ansiosa para acompanhar o máximo possível tudo o que acontecia na tarde da final do campeonato, perguntei por que ela não se juntava às outras mulheres que também acompanhavam seus namorados e maridos. Imediatamente, Fernando respondeu que as mulheres dos jogadores dos diferentes times não se misturam. Assim como dentro de quadra o campeonato é regido por regras as do futebol -, do lado de fora também há um conjunto de códigos que rege a dinâmica de interação dos grupos. Cada peruano que participa da Copa Peru-Rio tem seu grupo, 
que define, com suas namoradas e amigos, um local específico no entorno da quadra em que vão ficar, esperando sua vez de jogar. O contato com outros grupos é mais ou menos esporádico e superficial. Fernando deixou claro, para mim, que fora da quadra também havia regras a serem respeitadas. Algum tempo depois, a namorada de outro jogador do time de Fernando chegou e, assim, fez companhia à namorada dele, o que me permitiu circular sem que ela reclamasse minha presença.

Assim, participar do mesmo campeonato de futebol e dividir o espaço dentro de quadra não garante, por si só, uma integração mais profunda entre os peruanos. Embora compartilhem do entusiasmo pelo futebol, eles formam equipes adversárias dentro das quadras. Fora delas, os competidores se reúnem em pequenos grupos de acordo com o time em que jogam, que, por sua vez, expressa o grupo de afinidade no qual estão inseridos. Dentro destes grupos menores, os peruanos se preparam para a partida, se concentram, conversam e comem juntos. Estes grupos não são completamente fechados: eventualmente, pessoas de diferentes grupos conversavam, mas, em seguida, voltavam para aquele com o qual tinham mais intimidade.

A Copa Peru-Rio 2011 foi muito emblemática para que eu pudesse refletir sobre a relação dos peruanos entre si e a cidade. No primeiro momento, o que me saltou aos olhos na relação entre os times que disputavam o campeonato era a questão de classe. Desde meus primeiros contatos, sempre ouvi deles que é muito comum não se relacionarem com outros compatriotas por variados motivos, como a origem geográfica, étnica, ou o trabalho que desenvolvem. A distância entre o time dos vendedores ambulantes cusquenhos e o dos ex-estudantes universitários parecia comprovar tal diagnóstico. Esta observação me fez suspeitar que a relação entre os times de futebol e a classe dos participantes não deixa de entrar em cena em momentos lúdicos.

Na edição de 2012 da Copa Peru Rio, confirmei que a questão de classe não desaparece no contexto de imigração: ser um trabalhador ambulante ou um estudante de pós-graduação faz com que o indivíduo ingresse num time de trabalhadores ambulantes ou num de estudantes de pós-graduação. No entanto, a dinâmica de sociabilidade entre esses migrantes no Rio de Janeiro não se reduz à dimensão classe. Um exemplo disso é que em 2011, três equipes que disputaram o campeonato eram formadas 
por estudantes e ex-estudantes: uma de estudantes do Centro Brasileiro de Pesquisas Físicas (CBPF); outra, de alunos da PUC-RJ; a terceira, cujo nome é Peruchos, já mencionada, é composta de ex-estudantes universitários chegados ao Rio de Janeiro no mesmo período. Das três equipes, eu conhecia jogadores das equipes PUC-RJ e dos Peruchos. Percebi que entre eles não se estabelece um contato mais íntimo, assim como não há uma interação mais profunda entre os últimos e o time de Fernando - que eu havia conhecido em 2011.

A Copa Peru-Rio se mostrou a mim como uma metáfora das relações sociais entre os peruanos no Rio de Janeiro. A formação das equipes de futebol se estrutura nas redes de relações, por sua vez estabelecidas por múltiplos elementos: os lugares da cidade frequentados, o motivo por que saíram do Peru e vieram ao Rio, o bairro onde moram hoje, o bairro ou a cidade onde moravam no Peru, a principal atividade que exercem aqui, entre outros. Em outras palavras, a classe é um elemento importante na constituição das equipes. Ela é vivida na trajetória e se manifesta na realidade de forma complexa, distinguindo os indivíduos por sua forma de vestir, falar, pensar, se comportar e compreender o mundo (BOURDIEU, 2007), assim como sair do Peru e viver no Brasil.

Por isso, um estudante que estuda na PUC-RJ e mora na Gávea, tem como colegas de PUC-RJ outros peruanos que conheceu antes de vir Brasil, dificilmente participará dos jogos de futebol às quintas-feiras à noite no Aterro do Flamengo, organizados pelos peruanos vendedores ambulantes que moram na Lapa, ou os que acontecem na Urca, organizados pelos dos alunos do CBPF, mesmo sendo estes últimos estudantes de pósgraduação como ele. Quando perguntei se existia algum tipo de discriminação entre os peruanos que vivem no Rio de Janeiro, Renato, estudante de graduação, me respondeu:

É qual é teu círculo... Um estudante, por exemplo, ou alguém que trabalha, vai ficar com os peruanos que estão estudando ou trabalhando. E os artesões, porque há muitos peruanos artesãos, que inclusive jogam futebol no Aterro- dificilmente vão frequentar os mesmos lugares; por exemplo, este festival gastronómico no Sheraton ${ }^{1}$, de comida peruana. Poucos peruanos vão lá para comer. Um artesão nunca vai lá ou ao Inti

\footnotetext{
${ }^{1}$ Festival de comida latino-americana que acontece anualmente e que sempre tem um fim de semana exclusivo de comida peruana.
} 
Wasi²... Eu não sei se seria discriminação: são círculos sociais, econômicos ${ }^{3}$ (Tradução nossa).

Sua explicação sobre os círculos nos quais se inserem os peruanos no Rio de Janeiro complementa minhas reflexões sobre a Copa Peru-Rio. Elas foram primordiais para que eu refinasse meu olhar e minha escuta sobre a complexidade das relações sociais construídas pelos peruanos com outros peruanos, brasileiros e estrangeiros de outras nacionalidades. Sayad (1998) alerta que é um equívoco imaginar que os imigrantes formam uma comunidade coesa e unitária. Esta ideia parte da representação que se faz dos imigrantes como unidos aprioristicamente como grupo homogêneo. Esta representação se baseia no nosso desconhecimento sobre os imigrantes: “[...] a percepção ingênua e deveras etnocêntrica que se tem dos imigrantes como sendo todos semelhantes encontra-se no princípio dessa comunidade ilusória" (SAYAD, 1998, p. 85).

Na dinâmica do campeonato, os pequenos grupos que se reúnem no entorno do campo deixam nítidas as inúmeras diferenças que marcam a relação entre eles. Se as equipes de futebol são formadas a partir de grupos de afinidade que definem o "círculo" em que cada um estará inserido, como explica Renato, estes grupos não são formados de maneira aleatória, casual e contingente, tendo como única referência a nacionalidade peruana. Grande parte das equipes participantes da Copa Peru-Rio é composta a partir de um ou mais dos seguintes critérios: a) indivíduos que desenvolvem a mesma atividade de trabalho ou estudo; b) oriundos da mesma cidade ou bairro do Peru; c) que chegaram ao Rio de Janeiro no mesmo período; e) que trabalham, estudam ou moram próximo dos outros.

Em geral, a opção "a" funciona como um dos principais critérios para a formação dos grupos de afinidade que darão origem às equipes de futebol. Isso porque a atividade que motivou determinado indivíduo a vir ao Rio de Janeiro diz muito sobre sua posição de

\footnotetext{
2 Primeiro restaurante peruano no Rio de Janeiro, localizado no Flamengo.

${ }^{3}$ Es cual es tu circulo... Un estudiante, por ejemplo, o alguien que trabaja, va estar con peruanos que estan estudiando o trabajando. Y los artesanos - porque hay muchos peruanos artesanos que incluso juegan futbol en Aterro - dificil van a frecuentar los mismos lugares que, por ejemplo, este festival gastronomico en el Sheraton de la comida peruana. Pocos peruanos van a ir ahi a comer. Un artesano nunca va a ir ahi o al Inti wasi... No sé si seria discriminación: son círculos sociales, económicos.
} 
classe e os diferentes capitais - social, cultural (BOURDIEU, 2007) - que ele é capaz de acionar no Brasil e no Peru, principalmente quando o estrangeiro exerce no Brasil a mesma atividade que exercia no Peru.

Esta dinâmica também baliza a relação entre os peruanos e os brasileiros. Os peruanos das classes mais baixas, por exemplo, se relacionam e convivem com brasileiros também das classes mais baixas. No time dos irmãos cusquenhos, por exemplo, todas as namoradas eram brasileiras, migrantes internas que vieram ao Rio de Janeiro como trabalhadoras. Para se divertir, os irmãos cusquenhos gostam de frequentar a Feira de São Cristóvão, espaço popular, no Rio de Janeiro, de encontro das populações nordestinas. Já os peruanos de classe média que chegaram como estudantes universitários também se relacionam com brasileiros, mas que integram a classe média carioca escolarizada. Apesar de grande parte dos peruanos que frequentam a Copa PeruRio relatar ter um bom relacionamento com brasileiros, estes são presença rara nas partidas do campeonato, com exceção das brasileiras, esposas e namoradas dos jogadores. Os brasileiros que frequentam o Aterro do Flamengo, por sua vez, se mantêm afastados da área onde acontece o campeonato, demonstrando pouco interesse pelo evento.

Além da diferente relação que eles constroem com a sociedade brasileira, existem distinções entre eles que mantêm determinadas fronteiras físicas e sociais. Na pesquisa que realizei com peruanos que chegaram ao Rio de Janeiro como estudantes, alguns comentaram que percebem que os que têm o trabalho como principal motivação para sair do país enfrentam maiores dificuldades para se inserir na sociedade brasileira, seja o trabalho qualificado ou não. Em ambos os casos, os brasileiros tendem a vê-los como uma concorrência e uma ameaça. Além disso, há quem acredite que os peruanos que executam trabalhos mal remunerados e informais deixam uma má impressão do Peru no Brasil. Em resposta à pergunta: "Você acha que há diferença entre o peruano que vem ao Rio de Janeiro estudar e o que vem trabalhar?", um estudante peruano de doutorado respondeu: 


\begin{abstract}
Acho que tem diferença sim. Os peruanos que vêm estudar são assim, profissionais. Então, a cultura deles é um pouco diferente do peruano que vem só trabalhar. Muitas vezes o peruano que vem só trabalhar não tem muito [...] não tem profissão e eles vem praqui desenvolver trabalho, por exemplo, com bijuteria, vender coisas na rua... e às vezes, eles podem deixar uma má imagem do Peru aqui. Por exemplo, no Chile, tem muita gente que vai assim... eles (os peruanos) começaram a vender na rua; (os chilenos) falavam que eles faziam sujeira na rua [...] E aí começou um pouco de discriminação mais no Chile contra peruano, mas porque o peruano fazia coisas que davam motivo para chileno discriminar. Mas quem faz isso é mais a gente que vai só trabalhar, muitas vezes buscando oportunidade. Não tem oportunidade no Peru, não tem como estudar [...]
\end{abstract}

Na sua fala, o estudante deixa implícito que existe uma correlação entre ter uma profissão e transmitir uma imagem positiva do Peru no exterior. Ele explica que os peruanos que vão para o exterior trabalhar em atividades informais, como o comércio ambulante de bijuterias, muitas vezes contribuem para a má fama que os estigmatiza. 0 estudante entende a educação formal como uma maneira de acessar um tipo de "cultura" que permite que os peruanos assumam uma postura irrepreensível diante dos olhos da sociedade receptora. Insinua que a escolaridade e a profissão são critérios que moldam o modo de agir e pensar dos peruanos, a ponto de torná-los mais aceitáveis ao julgamento da sociedade brasileira. No entanto, o que ele não poderia prever é que, mesmo em cidades em que grande parte da população peruana é composta por peruanos de altíssimo nível de escolaridade, como o Rio de Janeiro, predomina sobre o Peru um imaginário negativo, associado principalmente à pobreza (DANIEL, 2013).

A análise do estudante de doutorado, que considera que peruanos altamente escolarizados, e que vão para o exterior como profissionais, possuem uma cultura particular, que vai deixar uma "boa imagem" do Peru no exterior, sugere que ele não gostaria de se relacionar com compatriotas que transmitem uma "má imagem" do Peru no Rio de Janeiro. Assim como ele, outros peruanos de classe média comentam que é comum os de classes mais baixas terem hábitos que maculam a imagem dos peruanos no exterior, como exagerar no consumo de bebidas alcoólicas e se envolver em brigas. Numa das partidas de futebol a que assisti na edição 2011 da Copa Peru-Rio, dois jogadores se desentenderam e começaram a se agredir a socos. Aos gritos das esposas e 
namoradas que formavam a torcida, os dois foram separados e a partida seguiu. Se, por um lado, alguns peruanos/as da classe média preferem evitar se relacionar mais intimamente com compatriotas que podem transmitir uma "má imagem" do país, os/as peruanos/as que chegaram ao Rio de Janeiro como imigrantes para trabalhar em ramos como o comércio informal e o trabalho doméstico preferem se relacionar com outras pessoas com quem compartilham uma posição de classe similar, mesmo que não sejam peruanos, caso de Fernando e seus amigos. Assim, os grupos de afinidades, as equipes de futebol e as pequenas agrupações que se formam no entorno do campo em que a Copa Peru Rio é disputada têm muito a dizer sobre as nuances e a profunda complexidade da experiência migratória dos peruanos no Rio de Janeiro e sua relação com a cidade.

\section{Considerações finais}

Além de constituir um importante espaço na sociabilidade dos/as peruanos/as no Rio de Janeiro, a Copa Peru-Rio também revelou ser uma peça relevante no processo de construção de territorialidades que Ihes permitem sentir o Rio de Janeiro como uma cidade familiar, do qual também fazem parte. Nela ocupando uma área tradicional para os praticantes amadores de futebol, o Aterro do Flamengo, os peruanos fazem do esporte tão popular no Brasil, e também no Peru, uma esfera de socialização entre peruanos em diáspora pela celebração de um símbolo do país de origem, a independência do país. Longe de significar uma escolha entre o país de origem ou o de destino, a Copa Peru-Rio traz, no próprio nome, o sentido de reunir diferentes territorialidades no contexto migratório, através do esporte e também de outros elementos que remetem ao Peru, como a comida vendida em todos os jogos no entorno do campo, a música que soa ao fundo, sempre em língua espanhola, e a dança folclórica, encenada nas finais do campeonato.

Na dinâmica do campeonato, o processo de apropriação cultural e simbólica do território é construída a partir da lógica urbana dominante no Rio de Janeiro, que tem a zona sul como área que concentra recursos, serviços públicos e áreas de lazer. Não é por 
acaso que um número significativo de peruanos que participa do evento reside em áreas da zona sul ou próximo a ela. Na maioria dos casos, é na região onde residem que também desenvolvem suas atividades de lazer, trabalho e estudo, tanto entre os peruanos de classe média ou alta, seja os das classes mais baixas, que, muitas vezes, vivem em favelas na zona sul carioca ou em moradias precárias da área central.

Além disso, o processo de reterritiorialização, quando acontece, não se dá num vazio, mas segundo estruturas e hierarquias sociais, como raça, classe e gênero, que perpassam a experiência migratória dos/as peruanos/as no Rio de Janeiro. Se tais hierarquias podem ser reproduzidas na imigração, o distanciamento físico do Peru, a inserção na sociedade brasileira e o encontro com outros modos de viver e pensar que o contexto urbano propicia trazem a potencialidade de desafiar estereótipos e desigualdades.

\section{Referências}

ALMEIDA, Ana Letícia Canegal. Entrando em campo: a "pelada organizada"no Aterro do Flamengo. 2012. Dissertação. 119 f. (Mestrado em Ciëncias Sociais) - Programa de Pósgraduação em Ciências Sociais, Pontifícia Universidade Católica do Rio de Janeiro, Rio de Janeiro, 2012.

ALTAMIRANO, Teofilo. Liderazgo y organizaciones de peruanos en el exterior: culturas transnacionales e imaginários sobre el desarrollo. v. 1. Lima: Pontifícia Universidad Católica del Perú, 2000.

BOURDIEU, Pierre. A Distinção: crítica social do julgamento. São Paulo: EdUSP; Porto Alegre: ZOUK, 2007.

BUSSE, Erika. Gendered social capital in the ethnic enclave: the paradox of peruvian immigrants' family reunification plans. In: ENCONTRO ANUAL. AMERICAN SOCIOLOGICAL ASSOCIATION, 106, Las Vegas, 2011. Anais eletrônicos. Las Vegas, 2011. Disponível em <http://citation.allacademic.com/meta/p506351_index.html>. Acesso em: 23 jun. 2013.

DA MATTA, Roberto. O ofício de etnógrafo, ou como ter "anthropological blues". In: NUNES, E. (Org.). A aventura sociológica. Rio de Janeiro (RJ): Zahar, p. 30-45, 1978. 
DANIEL, Camila. P'a crecer en la vida: a experiência migratória de jovens peruanos no Rio de Janeiro. 2013. 30of. Tese (Doutorado em Ciências Sociais) - Programa de Pósgraduação em Ciências Sociais, Pontifícia Universidade Católica do Rio de Janeiro. Rio de Janeiro, 2013.

COPA PERU-RIO [Internet]. Rio de Janeiro, 2014. Disponível em <http://www.copaperurio.com.br/2011/index.html>. Acesso em: 6 jan, 2014.

HAESBERT, Rogério. O mito da desterritorialização: do "fim dos territórios" à multiterritorialidade. Rio de Janeiro: Betrand Brasil, 2006.

LEFEBVRE, Henri. A revolução urbana. Belo Horizonte: UFMG, 2004.

PÆRREGAAD, Karsten. Peruvians dispersed: a global ethnography of migration. Plymouth: Lexington books, 2008.

SASSEN, Saskia. The global city: New York, London, Tokyo. Princenton: Princeton University Press, 2001.

SAYAD, Abdelmalek. A Imigração ou os paradoxos da alteridade. São Paulo: EdUSP, 1998.

SIMMEL, Georg. A metrópole e a vida mental. In: VELHO, O. (Org.). O fenômeno urbano. Rio de Janeiro: Zahar, 1979, p. 11-25.

TANAKA, M. Jóvenes: actores sociales y camibo generacional - De la acción colectiva al protagonismo individual. In: COTLER, J. (Org.). Perú: 1964-1994. Lima: IEP, 1995, p. 149166. 
Recebido em: 09/03/2014 Aprovado em: 15/05/2014 